\title{
Mandat Liga Bangsa-Bangsa : Kegagalan Palestina Menjadi Negara Merdeka (1920-1948)
}

\author{
Hanafi Wibowo ${ }^{1}$
}

\begin{abstract}
Abstrak
Artikel ini mengkaji Palestina pada masa Mandat Inggris melalui Metode Historis dengan Pendekatan Politik. Pasca Perang Dunia Pertama (1914-1918), Inggris mendapat mandat dari Liga Bangsa Bangsa untuk mengelola administrasi bekas wilayah wilayah Arab yang sebelumnya adalah bekas wilayah Turki Usmani. Di dalam proses pengelolaan ini, terjadi permasalahan dimana muncul dua kekuatan yang saling bertentangan yaitu Zionis Yahudi sebagai pendatang baru dan rakyat Palestina sebagai penduduk asli. Keinginan Liga Bangsa Bangsa yang menugaskan Inggris untuk memberikan masing masing kedua bangsa itu sebuah negara yang merdeka mendapat penolakan baik dari pihak Palestina maupun dari pihak Yahudi itu sendiri. Studi ini juga mempelajari dampak dari keberhasilan orang Yahudi mendirikan Israel diatas penderitaan rakyat Palestina. Artikel ini ingin menjelaskan mengapa Palestina mengalami kegagalan dalam mendirikan sebuah negara merdeka yang penulis dapatkan dari pelbagai sumber dan data-data tertulis. Menurut penelahaan penulis, era Mandat Inggris adalah akar dan awal kegagalan Palestina mendirikan negara merdeka, selain itu terdapat dua faktor penting penyebab kegagalan tersebut. Pertama, adalah faktor internal dari rakyat yang saat itu berupa adanya kesalahan strategi dari elit dan rakyat Palestina sendiri. Kedua yaitu faktor eksternal adalah campur tangan negara-negara Arab tetangga yang memecah Palestina demi kepentingannya.
\end{abstract}

Kata Kunci: Mandat Inggris, Palestina, Nasionalisme Arab.

\begin{abstract}
This article examines the period of the British Mandate of Palestine through the Historical Method and Political Approach. Post First World War (1914-1918), the British received the mandate from the League of Nations to manage the administration of the former Arab territories which previously was a former territories of the Ottoman Empire. In this management process, there is a problem which emerged two opposing forces, namely the Zionist Jews as newcomers and the Palestinians as natives. League of Nations assigned Britain to give each of the two nations was an independent country gets a rejection by the Palestinians and the Jews themselves. This study also studied the impact of the success of the Jews set up Israel over the plight of the Palestinians. This article wants to explain why the Palestinians have failed in establishing an independent state that the author got from various sources and data. According to the review of the author, the British Mandate era is the root and the beginning of the failure of the Palestinians to establish an independent state. There are two important factors causing this failure. First, the internal factors of the people who was in the form of an error in the strategy of Palestinians themselves. A second, external factor which the interference of neighboring Arab states (Jordan and Egypt) who partitioning the territories of Palestine.
\end{abstract}

Keyword: British Mandate, Palestine, Arab Nationalism.

\footnotetext{
${ }^{1}$ Fakultas Adab dan Humaniora Universitas Islam Negeri Syarif Hidayatullah Jakarta..
} 


\section{A. Pendahuluan}

Sejak tahun 1517 hingga 1917, Palestina dikuasai oleh Turki Usmani yang menempatkan Wilayah Palestina yang Mencakup Muttasharifate Jerusalem (Kudüs-i Şerif Mutasarrıfliğl) dan Kota Kota di Sekitarnya seperti Jaffa,Hebron \& Betlehem ke dalam Wilayah Provinsi Syria (Vilayet Syria) $^{2}$

Karena situasi dalam negeri yang lemah menyebabkan, Turki Utsmani tidak berminat ikut serta dalam Konflik Militer apapun. Namun Sultan Utsmani saat itu, Mehmed V Reşad tidak lebih dari boneka menggantikan Abdülhamid II, yang digulingkan pada tahun 1908 dan digantikan dengan pemerintahan militer yang dipimpin oleh Enver Pasha dan Talat Pasha. Akhirnya, Pada tanggal 22 Juli 1914, Turki Usmani mengajukan tawaran Aliansi kepada Jerman. Wilhelm II, German Emperor \& King of Prussia menerima tawaran itu pada tanggal 2 Agustus 1914. Maka Turki Usmani resmi bergabung dengan Blok Sentral. ${ }^{3}$

Salah satu strategi Inggris melawan Aliansi German-Usmani adalah mengajak Bangsa Arab untuk melawan Usmani. Mereka menemukan pembantu yang siap dan bersedia melakukan hal itu di Hijaz, yaitu Sharif Hussein bin Ali, yakni Emir dari Makkah yang menandatangani perjanjian dengan pemerintah Inggris untuk memberontak melawan Imperium Utsmani. Inggris berjanji kepadanya bahwa setelah perang, dia akan diberi kerajaan Arab tersendiri yang akan mencakup seluruh Semenanjung Arab, termasuk Suriah dan Irak. Surat-surat di mana kedua belah pihak menegosiasikan dan membahas pemberontakan ini dikenal

\footnotetext{
${ }^{2}$ Dror Zeevi, An Ottoman century : the district of Jerusalem in the 1600s, (Albany: State University of New York Press, 1996), h. 121.

${ }^{3}$ H.S.W Corrigan, "German-Turkish Relations and the Outbreak of War in 1914: ReAssessment", Past and Present, Vol. 0, h.144152
}

sebagai Korespondensi McMahon Hussein, saat Sharif Hussein berkomunikasi dengan Komisaris Tinggi Inggris di Mesir, Sir Henry McMahon. ${ }^{4}$

Pada tahun 1918 perang berakhir dengan kemenangan Sekutu yang segera menghancurkan Turki Usmani lewat Perjanjian Sevres, bersamaan dengan itu Wilayah Timur Tengah dibagi-bagi oleh Sekutu yaitu Prancis \& Inggris yang sejak awal sudah merencanakannya. Prancis mendapat wilayah Levant sedangkan Inggris memperoleh Vilayet Iraq, Transjordan dan Palestina. Perjanjian ini jelas bertentangan dengan janji Inggris yang dibuat bagi Sherif Hussein.Namun, hal ini tidak menjadi satu-satunya perjanjian yang bertentangan dan yang terakhir yang dibuat Inggris. 5

Sebagai dampak langsung dari Perang Dunia I, Liga Bangsa-Bangsa (yang merupakan cikal bakal PBB) didirikan. Salah satu pekerjaannya adalah untuk memecah Provinsi-Provinsi Utsmani yang ditaklukan. Liga Bangsa-Bangsa (LBB) menyusun "mandat" bagi dunia Arab. Setiap mandat dikuasai oleh Inggris atau Perancis "sampai saat mereka mampu berdiri sendiri."Sesuai yang telah disepakati dalam Perjanjian Sykes-Pycott maka Inggris juga menerima wilayah Palestina.

Namun, pada tahun 1917, Inggris sudah terlebih dahulu memberikan janji pada kelompok Zionis untuk mendukung berdirinya Jewish national Homeland di Palestina.

Pada tanggal 24 April 1920, pihak sekutu sebagai pemenang Perang Dunia Pertama mengadakan pertemuan di San Remo, Italia. Liga Bangsa-Bangsa memutuskan bahwa wilayah-wilayah pendudukan belum siap untuk diberi

\footnotetext{
${ }^{4}$ Hussein-McMahon Correspondence, dari Jewish Virtual Library.

${ }^{5}$ Matthew Hughes, Allenby \& British Strategy in the Middle East 1917-1919,(London : Taylor \& Francis, 1999), h.122-124
} 
kemerdekaan, maka harus diurus oleh administrasi sipil yang disebut 'Mandat'. Sesuai dengan yang telah disepakati sebelumnya dalam Perjanjian Sykes-Pycot tahun 1916, Inggris mendapat mandat atas wilayah Palestina dan Transjordania ${ }^{6}$.

Menurut Duta Besar Palestina untuk Republik IndonesiaM Fariz al Mehdawi, Mandat adalah sebuah Supervisi. Ibaratnya, seperti anak yang kehilangan orangtuanya dan diasuh oleh orang lain sampai siap hidup mandiri. Negara pemegang Mandat, dalam hal ini Inggris bertanggung jawab pada Liga BangsaBangsa untuk menyiapkan Palestina agar siap diberi kemerdekaan ${ }^{7}$

Mandat Inggris di Palestina dipimpin oleh seorang Komisaris Besar bernama Herbert Samuel yang pada masa kepemimpinannya, Samuel memberikan amnesti kepada Amin Al- Husayni ${ }^{8}$ yang saat itu sedang mendekam di penjara". Setelah bebas, Al- Husayni dilantik oleh Herbert Samuel menjadi Mufti Agung Palestina (Mufti Filastin al-Akbar). Selain itu, Herbert Samuel mendirikan Dewan Tinggi Muslim (Supreme Moslem Council) yang bertugas mengatur dan menjaga lembaga-lembaga dan komunitas Islam di Palestina. Dalam lembaga ini, Amin al-Husayni diangkat menjadi pimpinan pertamanya ${ }^{9}$

\footnotetext{
${ }^{6}$ Article 22, The Covenant of the League of Nations and "Mandate for Palestine," Encyclopedia Judaica, Vol. 11, hlm. 862, Keter Publishing House, Jerusalem, 1972

${ }^{7}$ Wawancara Pribadi dengan Duta Besar Palestina untuk Republik Indonesia, Fariz al Mehdawi, Jakarta 4 Juli 2014.

${ }^{8}$ Amin al-Hussayni adalah loyalis Raja Faisal yang terusir dari Syria oleh Pemerintah Mandat Prancis. Ia adalah anggota salah satu klan Aristokrat yang cukup berpengaruh di Palestina, ia juga dikenal sebagai paman dari Yasser Arafat. Namun, ia dipenjara karena terlibat dalam "Pemberontakan Nabi Musa" tahun 1920. ${ }^{9}$ Martin Kolinsky. Law,Order\& Riots in Mandatory Palestine 1929-1935. (London : St Martin's Pres,2010), h.86
}

Samuel jelas bersikap kooperatif terhadap aspirasi masyarakat Arab Palestina. Hal itu menyebabkan ia mendapat kecaman dari penduduk Yahudi. Walaupun Samuel telah menetapkan bahasa Ibrani menjadi salah satu dari 3 bahasa resmi Palestina (kedua lainnya adalah Arab dan Inggris) ${ }^{10}$, namun penduduk Yahudi tetap saja mengecamnya karena ia menunjuk Amin al-Husayni yang tidak populer di kalangan masyarakat Yahudi.

Dari uraian di atas, ada beberapa hal yang menurut penulis menarik untuk diteliti, yaitu Posisi Palestina yang Strategis di Mata Inggris, namun Pemerintah Inggris masih mencoba mengikuti Perintah Liga Bangsa Bangsa untuk mempersiapkan Palestina menjadi Negara Merdeka bagi Etnis di dalamnya, yaitu Arab selaku Penduduk asli dan Yahudi sebagai Pendatang. Namun Akhirnya hanya Israel yang bisa berdiri sedangkan Palestina gagal.

Dipilihnya Palestina sebagai Objek Kajian dikarenakan Palestina nota bene sebagai tempat yang sangat penting baik secara praktis maupun simbolis. Dari zaman ke zaman, puluhan imperium memperebutkan Palestina dan Kota Suci di dalamnya demi tujuan indroktinasi agama maupun legitimasi Kekuasaa.

Adapun dipilihnya Mandat Inggris sebagai Objek Kajian, karena Penulis memiliki akses terhadap Sumber Sumber Tertulis terutama Arsip dalam bahasa Inggris mengenai Kebijakan Mandat Inggris dan Reaksi Perlawanan Bangsa Arab. Selain itu, dari Sumber Sumber Tertulis, Peneliti menelaah bahwasanya Periode Mandat Inggris merupakan awal dan akar kegagalan Palestina Menjadi Negara Merdeka yang menyebabkan konflik berkepanjangan hingga hari ini.

\footnotetext{
${ }^{10}$ Norman Bentwich. "The Legal System of Palestine under British Mandate".Middle East Journal,Vol.2 no.1 (Jan 1948), h.33-46
} 


\section{B. Pembahasan}

\section{Perlawanan Rakyat Palestina : Konflik Tembok Ratapan}

Bagi umat Yahudi, Tembok Barat, atau yang lebih dikenal dengan Tembok Ratapan, merupakan satu-satunya bagian yang tersisa dari Haikal Solomon yang dihancurkan oleh Imperium Romawi pada tahun 70 Masehi. Bangunan tersebut merupakan peninggalan Israel kuno yang sangat penting dan religius bagi umat Yahudi. Bagi umat Islam tembok tersebut merupakan batas luar kawasan Haram AlSharif. Kawasan tersebut merupakan kawasan suci tempat terdapatnya The Dome of the Rock (Kubat as-Sakrah) dan Masjid al-Aqsa, masjid tersuci ketiga bagi umat Islam (Thalith al-Haramain) ${ }^{11}$.

Menurut Duta Besar Palestina, Fariz al Mehdawi, Masjid al-Aqsa memiliki arti yang sangat penting bagi Umat Islam, karena merupakan Kiblat Pertama Umat Islam (Ula al-Qiblatain). Yang kedua, Masjid al-Aqsa adalah bangunan kedua yang dibangun oleh Nabi Adam selain Ka'bah setelah dirinya terusir dari Surga ${ }^{12}$.

Pada tanggal 15 Agustus, sejumlah imigran Yahudi dibawah kepemimpinan Jeremia Halpern berbaris menuju Tembok Ratapan sambil mengibarkan bendera Zionis dan menyanyikan Hatikvah (Hymne Yahudi). Pada tanggal 23 Agustus 1929, huru-hara pun pecah antara Yahudi dan Arab di Jerusalem dan dengan cepat menyebar ke wilayah lain. Kerusuhan ini berlangsung selama seminggu dan mengakibatkan jatuhnya banyak korban, baik dari pihak Yahudi maupun Arab. Pada hari terjadinya kerusuhan, sebuah rumor beredar di pihak Arab Palestina bahwa Mufti Amin al Hussayni meminta mereka

\footnotetext{
11 Trias Kuncahyono, Jerusalem: Kesucian, Konflik, dan Pengadilan. (Jakarta : Penerbit Kompas, 2009), h.33-34

${ }^{12}$ Wawancara Pribadi dengan Duta Besar

Palestina, Fariz al Mehdawi, Jakarta 4 Juli 2014.
}

untuk melidungi masjid di kawasan Haram Al-Sharif karena kaum Yahudi berencana menyerang tempat tersebut ${ }^{13}$.

Salah satu wilayah yang terkena imbas kerusuhan ini adalah Hebron. Kota Hebron dianggap penting dalam kepercayaan Islam dan Yahudi karena tempat ini diyakini merupakan tempat tinggal Nabi Ibrahim di masa lalu ${ }^{14}$. Pada tahun 1929, populasi kota ini sebanyak 20 ribu jiwa, mayoritas adalah muslim Arab. Ada pula komunitas Yahudi sebanyak 700 orang yang tinggal di Hebron dengan menyewa rumah dari penduduk Arab.

Kerusuhan di kota Hebron menyebabkan 67 orang Yahudi termasuk 23 orang mahasiswa terbunuh akibat serangan orang orang Arab yang terpengaruh oleh rumor palsu bahwa orang Yahudi telah membantai orang-orang Arab di Jerusalem dan menduduki masjid Al Aqsa. Insiden ini menimbulkan kerusakan dan luka batin yang mendalam. Rumahrumah penduduk Yahudi dijarah dan sinagog-sinagog dirusak. ${ }^{15}$.

Pada tangal 29 Agustus 1929, selain di kota Hebron, kerusuhan juga menjalar ke kota Safed dan menewaskan 18-20 orang Yahudi yang bertempat tinggal di kota tersebut. David Hacohen sebagai saksi mata menceritakan peristiwa tersebut dalam buku hariannya ${ }^{16}$ :

"Orang-orang Yahudi lokal menceritakan padaku bagaimana tragedi ini bermula. Pada hari kamis tanggal 29 Agustus , orang-orang Arab di Safed dan juga dari desa tetangga membuat kerusuhan dengan membawa senjata serta galon bensin. Mereka membakar rumah-rumah, memenggal kepala

13 Ilan Pape. "Haj Amin \& Buraq Revolt", Jerusalem Quarterly File vol.6, no. 18 ,h.15

14 Edward Platt, The City of Abraham : History, myth \& Memory, a Journey through Hebron, (London : Pan Macmillan, 2012), h.5

${ }^{15}$ Noam Arnon, Hebron 4000 years and 40 : The Story of The City of Patriarch, (New York: The Hebron Fund,2009), h.22

${ }^{16}$ David Hacohen, Time to Tell : An Israeli Life 1898-1984.(New Jersey : Asscosciate University Press,1985), h.37-38 
penghuninya, mereka menghempaskan seorang anak ke dinding dan memotong tangannya. Seorang lelaki Yahudi bernama Yitzhak Mamon ditikam berkali-kali hingga tewas namun pihak berwajib tidak berbuat apa-apa."

Walaupun dampak kerusakan yang dilakukan orang-orang Arab sangat parah, tapi Pemerintah Mandat Inggris menuding bahwa perbuatan para Imigran Yahudi pada tanggal 15 Agustus merupakan pemicu utama konflik tersebut. Setelah peristiwa tersebut, Pemerintah Mandat Inggris mempublikasikan peraturan $\mathrm{Order}$ in Council 1929 yang menetapkan bahwa umat Islam Palestina memiliki hak tunggal atas kepemilikan Tembok Ratapan dan area sekitarnya dan kaum Yahudi dilarang membunyikan Shofar di Tembok tersebut ${ }^{17}$

Bagi masyarakat Yahudi, kerusuhan tahun 1929 terutama pembantaian yang terjadi di daerah Hebron \& Safed membuat komunitas Yahudi di Palestina dan juga seluruh dunia terkejut. Peristiwa ini membuat orang-orang Yahudi memutuskan untuk memperkuat organisasi Paramiliter Yahudi yang disebut Haganah, yang akan menjadi cikal bakal dari Israeli Defense Force (IDF) ${ }^{18}$. Dua tahun kemudian, Haganah juga akan terpecah menjadi organisasi paramiliter yang lebih radikal yaitu Irgun Zvai Leumi ${ }^{19}$. Dengan kata lain, rakyat Arab Palestina "sukses" menggali kuburannya sendiri dengan memperkuat musuh yang akan mengancam masa depannya kelak.

\section{Perlawanan Rakyat Palestina Jilid II : Pemberontakan 1936-1939}

Pemberontakan 1936-1939 adalah sekumpulan kerusuhan sporadis yang

\footnotetext{
17 Menachem Begin. The Revolt: Story of the Irgun. (New York: Henry Schuman,Inc., 1959), h. $87-88$

18 John Bowyer Bell. Terror out of Zion. (New Jersey : Transaction Publishers, 1976), h.5

${ }^{19}$ Yehuda Bauer. "From Cooperation to Resistance : The Haganah 1948-1936". Middle Eastern Studies, vol.2 no.3 (April 1966), h.182210
}

dilakukan para petani dan pejuang revolusioner di Palestina. Pemberontakan ini awalnya menggunakan metode 'Ketidaktaatan Sipil' (Civil Disobedience $)^{20}$ namun berevolusi menjadi perlawanan bersenjata yang terdiri atas sekumpulan kecil pengerusakan tanpa mengincar satu target spesifik, melainkan banyak target; antara lain orang Yahudi dan Pemerintahan Mandat Inggris.

Faktor utama penyebab Revolusi ini adalah munculnya seorang ulama karismatik asal Syria bernama Izzudin alQassam yang menganjurkan bagi rakyat Palestina agar melakukan konfrontasi terhadap kelompok Zionis dan Pemerintah Mandat Inggris ${ }^{21}$. Motivasi Izzudin alQassam menawarkan solusi alternatif yang radikal karena ia menilai Dewan Tinggi Muslim yang dipimpin Amin al-Hussayni tak serius dalam memperjuangkan kemerdekaan Palestina. Ia menyalahkan Dewan Tinggi Muslim yang lebih senang memperbaiki masjid dibanding membeli senjata $^{22}$.

Pada tanggal 20 November 1935, Izzudin al Qassam menghimpun 800 anggota Brigade Tangan Hitam untuk menyerang pelabuhan Haifa yang notabene adalah pusat perekonomian Inggris karena adanya jaringan pipa minyak di wilayah itu $^{23}$. Sayangnya, Izzudin al-Qassam tewas dalam baku tembak bersama dengan tiga anak buahnya. Sedangkan beberapa

\footnotetext{
20 Ralph Schoenemann, Mimpi Buruk Kemanusiaan : Sisi Gelap Zionisme. (Surabaya : Pustaka Progresif,1998),h.52

${ }^{21}$ Wawancara Pribadi dengan Duta Besar

Palestina untuk Republik Indonesia, Fariz al

Mehdawi, Jakarta 4 Juli 2014.

22 Uri M Kupferschmidt, The Supreme Muslim Council: Islam Under the British Mandate for Palestine. (Leiden : Ej brill,1987),h.251

${ }^{23}$ Ted Swedenburg. "Al-Qassam Remembered". Journal of Comparative Poetics. No.7 (spring 1987) h.7-24
} 
anggota Tangan Hitam yang masih hidup ditangkap oleh Polisi Inggris ${ }^{24}$.

Kematian Izzudin al-Qassam yang dianggap tragis membuat seluruh lapisan rakyat Palestina berkabung, sehingga penguburan jenazahnya diselenggarakan layaknya upacara resmi kenegaraan. Izzudin al-Qassam dianggap sebagai martir oleh rakyat Palestina. Kematiannya menjadi pemicu bagi rakyat Arab Palestina untuk memberontak melawan Pemerintah Mandat Inggris ${ }^{25}$ sekaligus mentransformasi perlawanan rakyat Palestina menjadi pemberontakan bersenjata untuk beberapa dekade selanjutnya ${ }^{26}$.

Pada tanggal 15 April 1936, salah satu murid Izzudin al-Qassam yang bernama Farkhan al-Sa'adi, bersama anak buahnya membajak sebuah bus di kota Nablus dan menembak mati dua orang warga sipil Yahudi yang berada di dalam bus tersebut. Sore harinya, Haganah membalas dendam dengan membunuh dua orang petani Arab. Insiden ini menimbulkan ketegangan diantara kedua kelompok dan memicu bentrokan fisik yang berkelanjutan ${ }^{27}$. Akibatnya, Pemerintah Mandat Inggris langsung mengumumkan jam malam bagi warga sipil di kota Jaffa dan Tel Aviv. Bahkan selanjutnya Pemerintah Mandat Inggris memberlakukan keadaan Darurat Militer di seluruh kawasan Palestina. Pada tanggal 20 April 1936, sejumlah elit Palestina mendirikan Komite Arab Tertinggi ( $A l$ Lajnah al Arabiyah al-Uliya) di kota Nablus, yang mendeklarasikan Perlawanan

\footnotetext{
${ }^{24}$ Rashid Khalidi. Iron Cage : Palestinian Struggle for Statehood.( Oxford : One World Publication, 2007), h.90

${ }^{25}$ Ted Swedenburg. "Al-Qassam Remembered". Journal of Comparative Poetics. No.7 (spring 1987) h.7-24

${ }^{26}$ Fariz al Mehdawi. Derita Palestina Air Mata Kita. Jakarta : Cendikiawan Marhaen., t.t. h.6

${ }^{27}$ William Cleveland \& Martin Burton . History of Modern Middle East. (Philadelphia : Westview Press, 2009),h.258
}

rakyat Arab Palestina terhadap Pemerintah Mandat Inggris ${ }^{28}$.Komite ini menuntut agar imigrasi Yahudi dihentikan dan Pemerintah Mandat Inggris tak boleh lagi menjual tanah pada Imigran Yahudi serta dibentuknya pemeritahan sendiri bagi orang Arab Palestina yang akan bertanggung jawab pada Parlemen Inggris $^{29}$.

Pada tanggal 7 Mei 1936, Komite Arab Tertinggi menghimbau agar semua rakyat Arab Palestina yang bekerja di kantor-kantor pemerintah maupun perusahaan perusahaan di seluruh wilayah Palestina melakukan mogok kerja, serta tak perlu lagi membayar pajak kepada Pemerintah Mandat Inggris. Dengan ini, dimulailah 'Pemogokan Umum di Palestina' (Palestine General Strike) yang menjadi tahap awal dari Pemberontakan tahun $1936^{30}$

Pemerintah Mandat Inggris segera memberlakukan Hukum Darurat Militer. Orang orang yang dicurigai terlibat dalam pemogokan ditangkapi, Pemerintah juga mengenakan denda pada desa-desa yang warganya terlibat dalam pemogokan ${ }^{31}$.

Pemerintah Mandat Inggris kemudian meminta bantuan para pemimpin dunia Arab untuk menyelesaikan masalah ini. Pada tanggal 10 November 1936, Raja Ghazi dari Irak, Raja Abdul Aziz dari Arab Saudi dan Emir Abdullah dari Transjordania mengeluarkan "Seruan Bersama" yang memberikan himbauan agar : "menghentikan pemogokan dan menyerahkan proses politik kepada "niat baik" Pemerintah Inggris, yang berjanji akan melaksanakan

\footnotetext{
28 Taysir Nashif. "Palestinian Arab \& Jewish Leadership in Mandate Period". Journal of Palestine Studies. Vol.6 no.4, h.113-121

${ }^{29}$ Abdel Aziz Ayyad. Palestine Nationalism \& Palestinian. (Jerussalem : Palestinian academic study of international affairs, 1999), h.155

${ }^{30}$ Ralph Schoenemann, Mimpi Buruk Kemanusiaan : Sisi Gelap Zionisme. (Surabaya : Pustaka Progresif,1998), h.52

31 Ibid, h.53
} 
keadilan dan menghilangkan tindakan diskrimatif atas seluruh warga Palestina" $" 32$.

Karena adanya "Seruan Bersama" para pemimpin Arab itu akhirnya Amin al Hussayni selaku pemimpin Komite Arab Tertinggi memutuskan untuk menghentikan pemberontakan dan menghimbau kepada seluruh anggota pemberontak untuk meletakkan senjata ${ }^{33}$.

Pada tahun akhir tahun 1936, dibentuk sebuah Komisi Kerajaan yang dipimpin oleh William Peel yang bergelar $1^{\text {st }}$ Earl of Peel. Tugas utama dari Komisi Peel adalah menemukan penyebab pemberontakan ini. Komisi Peel kemudian menyimpulkan bahwa pemberontakan tahun 1936 disebabkan karena bangkitnya nasionalisme Palestina, ketakutan terhadap rencana pihak Yahudi mewujudkan "Jewish National Homeland", dan ketidakpercayaan masyarakat Arab Palestina terhadap niat baik Pemerintah Mandat Inggris. Komisi Peel kemudian merekomendasikan agar sebaiknya wilayah Mandat Inggris di Palestina dibagi menjadi dua, satu bagian untuk bangsa Yahudi dan satu bagian lainnya diberikan bagi bangsa Arab. Wilayah Yahudi, meliputi kawasan pantai, Lembah Jezreel, Beit She'an, dan Galilea, sementara Negara Arab akan meliputi Transjordania, Yudea, Samaria, Lembah Sungai Jordan dan Gurun Negev ${ }^{34}$.

Komite Arab Tertinggi yang dipimpin Amin al-Hussayni terangterangan menolak rekomendasi Komisi Peel dan menganggap Komisi Peel melanggar janji. Mereka mengeluarkan memorandum yang menyatakan bahwa Palestina adalah bagian integral dari dunia

\footnotetext{
32 Abdel Aziz Ayyad. Palestine Nationalism \& Palestinian. (Jerussalem : Palestinian academic study of international affairs, 1999), h.162

${ }^{33}$ Artikel di Koran Filastin, 13 November 1936

${ }^{34}$ Text Peel Comission Repot, https://www.jewishvirtuallibrary.orgHistory/pee 11.html, diakses pada 14 Mei 2014
}

Arab, karena itu usulan untuk memberikan sebagian wilayah Palestina kepada Imigran Yahudi bukanlah hal yang dapat diterima ${ }^{35}$.

Pada bulan Juni 1937, kerusuhan terulang kembali. Sejumlah milisi Arab membunuh Kepala Distrik Galilea, Lewis Andrews dan Pejabat Inggris bernama P.R. McEwen di luar gereja Anglikan di kota Nazareth. Pemerintah Mandat Inggris menyalahkan Komite Arab Tertinggi atas kerusuhan ini dan pembunuhan sejumlah Pejabat Pemerintah $^{36}$.

Komisaris Besar Mandat Inggris, Sir Arthur Grenfell Wauchope mengambil tindakan tegas dengan mengklasifikasikan Komite Arab Tertinggi sebagai Organisasi Terlarang. Amin al Husayni selaku pemimpin organisasi, melarikan diri ke Lebanon, sedangkan para pemimpin militer lainnya banyak yang ikut melarikan diri, atau terbunuh. Dengan hilangnya para Pemimpin, Gerakan Nasionalisme Palestina pun menjadi lemah karena absennya figur pemimpin ${ }^{37}$.

Pada bulan November 1937, pusat aktivitas para pemberontak berpidah ke kota Damaskus, Syria dengan berdirinya Komite Sentral Jihad Nasional Palestina (Al-Lajnah al-Markaziyya lil-Jihad). Pendiri organisasi ini adalah Izzat Darwaza, yang juga pendiri Partai Kemerdekaan Arab (Hizb al-Istiqlal alArabi). Para pemimpin pemberontakan yang melarikan diri dari Palestina seperti

\footnotetext{
${ }^{35}$ Abdel Aziz Ayyad. Palestine Nationalism \& Palestinian. (Jerussalem : Palestinian academic study of international affairs, 1999), h.166

${ }^{36}$ Ghassan Kanafani, The 1936-1939 Revolt in Palestine. (New York : Comitee for Democratic Palestine, 1972),h.47

${ }^{37}$ Michael J. Cohen. "Sir Arthur Wauchope, the Army, and the Rebellion in Palestine 1936". Middle Eastern Studies, Vol. 9, No. 1 (Jan., 1973), h. 19-34
} 
Jamal al Husayni, Fawzi al-Qawuqji dan Farkhan al-Saadi juga ikut bergabung ${ }^{38}$.

Dimulailah fase kedua dalam pemberontakan Arab Palestina. Jika pemberontakan pada fase pertama Komite Arab Tertinggi mengorganisir rakyat untuk melakukan pemogokan, fase kedua ditandai dengan pemberontakan yang dilakukan para petani (Fellahin) yang bergerak dalam unit-unit kecil sesuai dengan desa asal mereka masing masing dan dipimpin oleh $^{39}$ sejumlah komandan yang ditunjuk oleh Komite Sentral Jihad Nasional Palestina

Pada tanggal 2 Oktober 1938, 70 orang pemberontak Arab memasuki wilayah Kiryat Shmuel di kota Tiberias dan membantai 19 orang Yahudi, membakar rumah-rumah orang Yahudi beserta synagog di lingkungan tersebut. Di sebuah rumah, seorang ibu beserta kelima anaknya terbunuh, seorang Rabbi ditikam hingga tewas di dalam synagog. Pada saat terjadinya pembantaian, hanya terdapat 15 orang anggota Haganah yang bertugas sebagai penjaga untuk 2000 orang warga. Penyergapan oleh pemberontak pun terjadi dan menewaskan Mayor Isaac Zaki Alhadif dari Haganah ${ }^{40}$.

Ditengah situasi yang memanas, Sir Arthur Grenfell Wauchope mengundurkan diri dari jabatannya sebagai Komisaris Besar, ia digantikan oleh Sir Harold McMichael. McMichael memutuskan untuk melakukan perlawanan dengan mengirimkan 20.000 tentara ke garis depan yang terdiri atas Royal Air Force dan Royal Navy serta dibantu oleh Pasukan

\footnotetext{
${ }^{38}$ Wendy Pearlman. Violence, Nonviolence, and the Palestinian National Movement. (Cambridge : Cambridge University Press,2011), h.49-52

39 Abdel Aziz Ayyad. Palestine Nationalism \& Palestinian. (Jerussalem : Palestinian academic study of international affairs, 1999), h.171

${ }^{40}$ Aharon Kleva Kleiberger, Aurochtonous Text in the Arabic Dialect of the Jews in Tiberias. (Wiesbaden : Otto Harasowitz Verlag,2009),h.119
}

Paramilter Yahudi seperti Haganah dan Irgun $^{41}$.

Pemberontakan Arab Palestina tahun 1936-1939 adalah pemberontakan yang terbesar dalam sejarah Palestina, namun berakhir dengan kegagalan. Seperti halnya kerusuhan tahun 1929, pemberontakan tahun 1936-1939 menghasilkan dampak yang sangat krusial bagi masyarakat Arab Palestina secara keseluruhan. Pemberontakan ini menghabiskan semua energi dan sumber daya yang sangat dibutuhkan, karena bertempur melawan musuh yang masih kuat $^{42}$. Pihak Zionis mendapat keuntungan karena mempertahankan sikap kooperatif dengan Pemerintah Inggris dan akhirnya mereka dapat mengambil peluang dari momen melemahnya Inggris pada tahun 1947-1948. Sementara rakyat Arab Palestina yang masih belum pulih akibat kekalahan dalam pemberontakan ini, kehilangan momentum yang berharga ${ }^{43}$. Dapat disimpulkan bahwa Pemberontakan Arab Palestina tahun 1936-1939 adalah tindakan yang terburu-buru, sia-sia dan berakhir anti-klimaks.

\section{Pembagian Palestina dan Berdirinya Negara Israel}

Pasca perang dunia kedua, pihak Sekutu (Amerika-Inggris-Prancis-Uni Soviet) selaku pemenang perang merasa perlu membentuk Tatanan Dunia Baru (New World Order). Hal tersebut hanya bisa direalisasikan dengan membentuk organisasi persatuan dan perdamian international seperti Liga Bangsa-

\footnotetext{
41 Matthew Hughes. "From Law \& Order to Pasification : Britains Supression of Arab Revolt in Palestine 1936-1939". Journal of Palestine Studies. Vo.39 no.2 (Winter 2010) h.6-22

${ }^{42}$ W.F. Abboushi. "The Road to Rebellion Arab Palestine in the 1930's". Journal of Palestine Studies. Vol.6 no.3 (Spring 1977),h.23-46

${ }^{43}$ Rashid Khalidi. Iron Cage : Palestinian Struggle for Statehood. (Oxford : One World Publication,2007), h.123
} 
Bangsa $^{44}$. Namun, Liga Bangsa-Bangsa bersikap lemah ketika Nazi Jerman mencaplok Cekoslovakia dan Fasis Italia mencaplok Ethiopia ${ }^{45}$. Maka Liga BangsaBangsa harus dirombak menjadi organisasi yang jauh lebih kuat.

Upaya pihak Sekutu itu dicetuskan dalam Konferensi Yalta, di Krimea, Russia Selatan. Pihak sekutu sepakat untuk meneruskan perundingan di San Fransisco, Amerika Serikat. Perundingan berlangsung antara 25 April 1945 sampai dengan 26 Juni 1945 dan menghasilkan Piagam Perdamaian (Charter of Peace). Setelah diratifikasi pada tanggal 24 Oktober 1945, Piagam tersebut mulai diberlakukan dan menandai lahirnya Perserikatan BangsaBangsa (PBB) ${ }^{46}$

Perang dunia kedua juga mengakibatkan terjadinya dekolonisasi di seluruh kawasan Asia-Afrika. Aspirasi kemerdekaan nasional di hampir semua negeri yang tunduk pada kekuasaan Eropa semakin kuat. Dimulai dari Indonesia pada tahun 1945, efek domino dari dekolonisasi mulai menerpa negara-negara Asia lain. Angin kemerdekaan tersebut akhirnya sampai juga di Timur Tengah ${ }^{47}$.

Sebelum terjadinya dekolonisasi Timur Tengah, negara-negara Arab di kawasan itu sudah berencana menciptakan organisasi persatuan regional. Pada tanggal 7 Oktober 1944, perwakilan enam negara

\footnotetext{
${ }^{44}$ Michael Barnett. "Bringing in the New World Order: Liberalism, Legitimacy, and the United Nations". World Politics, Vol. 49, No. 4 (July 1997),h. 526-551

${ }^{45}$ C. G. Fenwick,"The Failure of the League of Nations", The American Journal of International Law, Vol. 30, No. 3 (Jul., 1936), h. 506-509

46 Robert C. Hilderbrand, Dumbarton Oaks : The Origins of the unite nations and the Search for Postwar Security (Chapell Hill : University of North Carolina Press, 2001),h.30

${ }^{47}$ Prof.Dr.Johan Hendrik Meuleman, Dinamika Abad ke 20, dalam Ensiklopedia Islam. Dinamika Masa Kini. (Jakarta : PT.Ikhtiar Baru van Hoeve,2002), h.10
}

Arab yaitu Arab Saudi, Mesir, Syria, Irak, Transjordan dan Lebanon mengadakan pertemuan di Alexandria. Hasil dari pertemuan ini dikenal sebagai Protokol Alexandria dan berdasarkan Protokol Alexandria itu, mereka membentuk organisasi Persatuan Arab yang diberi nama Liga Arab (al-Jami'ah alArabiyyah $)^{48}$. Protokol Alexandria juga memuat poin penting mengenai masalah Palestina, antara lain : Palestina adalah bagian integral dari dunia Arab, Kemerdekaan Palestinan sangatlah penting untuk stabilitas dunia Arab, dibentuknya Arab National Fund untuk membantu Ekonomi rakyat ${ }^{49}$, wilayah Palestina memiliki "karakter Arab" (dihuni oleh orang-orang Arab dan menggunakan bahasa Arab sebagai bahasa sehari hari). Kesimpulan Liga Arab tersebut bertentangan dengan perjanjian SykesPycott pada tahun 1916 yang menegaskan bahwa Palestina tidak murni Arab (Cannot be said to be purely Arab), ditinjau dari sisi historis ${ }^{50}$. Liga Arab juga membentuk Komite Eksekutif Arab untuk Palestina yang bertugas mewakili dan menyuarakan kepentingan Palestina di kancah internasional $^{51}$.

Pada tanggal 7 Februari 1947, Sekretaris Luar Negeri Inggris, Ernst Bevin, mengumumkan di hadapan Kabinet bahwa Kerajaan Inggris tak dapat lagi meneruskan Mandat yang pernah diberikan oleh Liga Bangsa-Bangsa atas wilayah

\footnotetext{
${ }^{48}$ Adeed Dawisha. Arab Nationalism in the Twentieth Century from Triumph to Despair. (New Jersey : Princeton University Press,2009), h. 123

${ }^{49}$ Text Protokol Alenxadria, The Alexandria Protocol, http://www.mideastweb.org/alexandria.htm, diakses pada tanggal 1 Juli 2014

${ }^{50}$ Peter Mansfield, History of Middle East, (Pennsylvania : Pennsylvania University Press, 2009), h.234

${ }^{51}$ Ensiclopedia Britannica. The Islamic World : Religion,History \& Future. (London: Britannica, t.t), h.165
} 
Palestina. Dengan demikian, masalah Palestina harus diserahkan kepada Perserikatan Bangsa-bangsa (PBB) selaku penerus Liga Bangsa-bangsa ${ }^{52}$.

Pada tanggal 28 April 1947, Sidang Umum PBB memutuskan membentuk sebuah Pantia Khusus yang disebut United Nation Special Comitee On Palestine (UNSCOP) yang beranggotakan 11 orang untuk melakukan penyelidikan mengenai masalah Palestina. Pada tanggal 11 September 1937, UNSCOP mengajukan rekomendasi yaitu : Pembentukan Palestina merdeka untuk etnis Arab dan Yahudi $^{53}$, dan Mandat Inggris atas Palestina harus segera diakhiri ${ }^{54}$.

Pada tanggal 29 November 1947, PBB mengeluarkan Resolusi no.181. Resolusi tersebut memutuskan bahwa wilayah Mandat Inggris di Palestina dibagi menjadi dua, satu bagian untuk bangsa Yahudi dan satu bagian lainnya diberikan bagi bangsa Arab. Wilayah Yahudi, meliputi Jaffa, sampai Galilea, daerah pelabuhan Haifa sampai selatan Jaffa dan Gurun Negev. Sementara wilayah Arab meliputi Lembah Esdraelon sampai Beersheba, wilayah barat Galilea dan Jalur Gaza sampai perbatasan Mesir. Khusus untuk Jerusalem, tidak diberikan pada Israel atau Arab karena Jerusalem merupakan kota suci untuk 3 agama (Yahudi, Kristen, Islam) jadi diberikan status Corpus Separatum $^{55}$.

\footnotetext{
${ }^{52}$ Ritchie Ovendale. The Middle East since 1940. (London : Longman Publishing,1992),h. 40

${ }^{53}$ Baruch Kimmerling \& Joe S Migdal.The Palestinian People. (Massachusets : Harvard University Press,2003).h.147

${ }^{54}$ Termination of the British Mandat of Palestine.The International Law Quaterly.Vol.2 no.1 (spring 1948),h.57-60

${ }^{55}$ Corpus Separatum adalah Bahasa Latin yang artinya 'tubuh terpisah' . maksudnya, kota Jerussalem tak akan dikuasai oleh orang Arab maupun Yahudi, melainkan menjadi Kota International. Dikutip dari Rashid Khalidi. Iron Cage : Palestinian Struggle for Statehood.
} (Oxford : One World Publication,2007).h.125
Para anggota Komite Arab Tertinggi di Pengasingan, menolak Pembagian ini dan membuat Memorandum yang menyatakan bahwa Resolusi itu bertentangan dengan jiwa dari Piagam $\mathrm{PBB}^{56}$. Liga Arab, sebagai pihak yang mewakili Palestina juga terang-terangan menolak Resolusi PBB no.181, mereka menilai alokasi tanah tersebut tidak adil dan akan melakukan intervensi di Palestina ${ }^{57}$. Sementara itu, Amin al Hussayni yang ketika itu berada di Mesir, mengeluarkan Deklarasi, menyerukan kepada seluruh masyarakat Arab di Timur Tengah untuk menyerang wilayah Mandat Inggris di Palestina dan menaklukkannya demi mencegah implementasi dari Resolusi PBB no. $181^{58}$

$$
\text { Pada akhir Desember 1947, }
$$

Pemerintah Mandat Inggris terkejut ketika Abdul Qadir al-Hussayni, keponakan Amin al-Hussayni memimpin pasukan Jihad al-Muqaddas ${ }^{59}$ bersama sejumlah sukarelawan dari Syria dan Lebanon berbaris memasuki batas wilayah Mandat Inggris $^{60}$. Liga Arab berencana mencegah PBB untuk melaksanakan Resolusi no.181. Pada bulan Januari- Februari tentara Arab Liberation Army (Jaysh al-Inqadh al-

\footnotetext{
${ }^{56}$ The Great Betrayal in United Nation : Memorandum to United Nation delegates. Arab Higher Committee Archive, Februari 1948. h.3

${ }^{57}$ Adeed Dawisha. Arab Nationalism in the Twentieth Century from Triumph to Despair. (New Jersey : Princeton University Press,2009), h. 131

${ }^{58}$ Deklarasi Amin al Hussayni untuk menyerang Palestina, dari Israeli defence Force Archive, file number 26/100001/1947

59 Jihad al-Muqaddas adalah sebuah gerakan yang berkarakteristik Islami dan nasional, dengan perlindungan dari al-Hajj Amin. Organisasi ini berpusat di kota Jerussalem dengan kepemimpinan Abdul Qadir al-Husaini dengan jumlah anggotanya hingga tahun 1935 sekitar 400 orang

${ }^{60}$ Karsh, Efraim. The Arab-Israeli Conflict.The Palestine War 1948, h.26-27
} 
Arabi $)^{61}$ dibawah pimpinan Fawzi alQawuqji menerobos perbatasan Palestina diikuti oleh 4000-5000 sukarelawan dari negara Arab yang lain ${ }^{62}$.

Dengan kehadiran Arab Liberation Army (Jaysh al-Inqadh al-Arabi) di Palestina untuk melakukan intervensi dan sikap organisasi paramiliter Yahudi yang bertekad mendukung Resolusi PBB no.181, menyebabkan terjadinya "Perang Sipil di Palestina" (Civil War in Palestine $)^{63}$. Orang orang Arab membunuh 41 pekerja Yahudi di penyulingan minyak Haifa, tentara Haganah membalas dengan menyerang desa Balad as-Sheikh dan membunuh 61 orang Arab ${ }^{64}$

Presiden Amerika, Harry Truman segera mengambil inisiatif dengan menawarkan rencana 'Perwalian untuk Palestina' (United States Proposal for Temporary United Nations Trusteeship for Palestine) selama 5 tahun mulai bulan Maret 1948, diakhirinya Mandat Inggris pada tanggal 15 Mei 1948, serta diberlakukannya gencatan senjata selama tiga bulan setelah melihat kenyataan bahwa Resolusi PBB no.181 mengakibatkan terjadinya perang sipil di Palestina ${ }^{65}$.

Situasi yang tenang karena adanya gencatan senjata ditambah fakta bahwa Mandat Inggris akan segera berakhir, dimanfaatkan David ben Gurion untuk mempersiapkan kemerdekaan Israel

\footnotetext{
${ }^{61}$ Arab Liberation Army (Jaysh al-Inqadh alArabi) adalah pasukan Liga Arab yang didirikan atas prakarsa Presiden Syria, Syukri al-Quwatli.

${ }^{62}$ Motti Goulani, The End of the British Mandate for Palestine in 1948: The Diary of Sir Henry Gurney, (London : Palgrave,2009), h.27

${ }^{63}$ Baruch Kimmerling \& Joe S Migdal.The Palestinian People. (Massachusets : Harvard University Press,2003),h.154

${ }^{64}$ The Black Paper on Jewish Agency \& Zionist Terrorism. Arab Higher Committee Archive, 12 Maret 1948. h.15

${ }^{65}$ Edward Buehrig. "UN,US \& Palestine". Middle East Journal. Vol.33 no.4 (Autumn 1979) h.434-453
}

secepat mungkin. Pemerintahan sementara pun dibentuk melalui Dewan Nasional yang merupakan penghubung antara Jewish Agency dan Komite Nasional

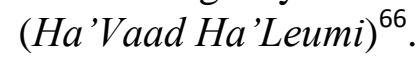

Sehari sebelum berakhirnya Mandat Inggris, tepatnya pada tanggal 14 Mei $1948^{67}$, Sir Alan Cunningham dan para Pejabat Pemerintahan Mandat Inggris meninggalkan Palestina dengan menaiki kapal dari Pelabuhan Haifa pada jam 8 Pagi $^{68}$. David ben Gurion memanfaatkan peluang ini dengan mengundang Komite Persiapan Urusan Kemerdekaan (Minhelet $\mathrm{Ha}^{\prime} \mathrm{Am}$ ) untuk menandatangani naskah Deklarasi Kemerdekaan Israel, yang akan ia bacakan pada Jam 4 Sore di Museum Tel Aviv ${ }^{69}$. Setelah pembacaan Deklarasi Kemerdekaan, Chaim Weizmann dilantik sebagai Presiden Israel pertama dengan David ben Gurion sebagai Perdana Menteri. Presiden Amerika saat itu, Harry Truman langsung memberikan pengakuan de-facto kepada Negara Israel yang baru berdiri $^{70}$.

Dengan dibentuknya Komite Eksekutif Arab untuk Palestina, Liga Arab menjadi pihak yang mewakili suara dan

\footnotetext{
${ }^{66}$ Elyakim Rubinstein. "The Declaration of Indepedendence as a Basic Documents of the State of Israel". Israel Studies. Vol.3 no.1 (spring 1998), h.183

${ }^{67}$ Pemilihan Tanggal 14 Mei 1948 oleh David ben Gurion dikarenakan tanggal 15 Mei 1948 bertepatan dengan 'Hari Sabbath'. Di masa kini, apabila Hari Kemerdekaan Israel bertepatan dengan 'Hari Sabbath', maka perayaannya akan dimajukan atau dimundurkan satu hari.

${ }^{68}$ Motti Goulani, The End of the British Mandate for Palestine in 1948: The Diary of Sir Henry Gurney, (London : Palgrave,2009), h.20

${ }^{69}$ Tuvia Frilling \& Ilan Troen. "Proclaiming Independence : Five Days in May from David ben Gurion's Diary". Israel Studies. Vol.3 no.1 (Spring 1998). h.196

${ }^{70}$ Michael Ottolenghi, "Harry Truman's Recognition of Israel". The Historical Journal. Vol.47 no.4 (Dec 2004),h.963
} 
kehendak Palestina ${ }^{71}$, sementara mereka kurang memahami aspirasi rakyat Palestina sesungguhnya, dan malah mendahulukan ambisi politiknya ${ }^{72}$. Rashid Khalidi berargumen, apabila rakyat Palestina mampu menyuarakan suaranya sendiri di saat akhir kekuasaan Mandat Inggris dan tidak menjadi Subaltern ${ }^{73}$, maka mereka pasti mampu mendirikan negara sendiri ${ }^{74}$.

Cara Israel memerdekakan diri pada detik detik yang menentukan, mirip seperti bangsa Indonesia yang memerdekakan diri saat terjadinya kekosongan kekuasaan pada tanggal 17 Agustus 1945. Bangsa Indonesia juga tidak menentang pembagian wilayah yang kurang adil dalam Perjanjian Linggarjati dan Renville, sehingga dunia internasional pun menaruh simpati atas kesabaran bangsa Indonesia, berbeda dalam kasus Palestina yang selalu menolak semua solusi dari Mandat Inggris maupun PBB sehingga pada akhirnya tidak banyak pihak yang bersimpati pada mereka $^{75}$.

\section{Perang Arab-Israel 1948}

Pada tanggal 15 Mei 1948, tentara koalisi dari lima negara Arab yaitu Syria, Jordania, Lebanon dan Irak menyerang Israel, pecahlah Perang Arab-Israel 1948. Invasi ini dilakukan sebagai respon Liga

\footnotetext{
${ }^{71}$ Ensiclopedia Britannica. The Islamic World : Religion,History \& Future. (London : Britannica, t.t.),h.165

${ }^{72}$ Joseph Nevo. "Arabs in Palestine 1947-1948 : Millitary \& Political Activity". Middle Eastern Studies. Vol.23 no.1 (Jan 1987),h.3-38

73 Pihak yang lemah dan tak mampu menyuarakan suaranya sendiri

${ }^{74}$ Rashid Khalidi. Iron Cage : Palestinian Struggle for Statehood. (Oxford : One World Publication,2007),h.126

${ }^{75}$ Joseph Nevo. "Arabs in Palestine 1947-1948 : Millitary \& Political Activity". Middle Eastern Studies. Vol.23 no.1 (Jan 1987,h.3-38
}

Arab atas Proklamasi Kemerdekaan Israel $^{76}$.

Jamal al Hussayni, sebagai Perwakilan Komite Arab Tertinggi di Pengasingan mengirimkan surat kepada Perwakilan PBB bahwa Pasukan yang dikirimkan oleh para anggota Liga Arab bertujuan untuk membela Hak Rakyat Palestina sebagai Mayoritas melawan Kolonisasi dari pihak Zionis Yahudi ${ }^{77}$.

Setelah perang yang berkepanjangan antara pasukan koalisi Arab melawan Israeli Defence Force (IDF), pasukan koalisi Arab ternyata kalah dalam perang tersebut. Pasukan IDF berhasil memukul mundur tentara koalisi Arab. Kemenangan Israel membuat mereka menguasai sebagian besar wilayah Mandat Inggris di Palestina. Perang ini diakhiri dengan deklarasi genjatan senjata dan dibuatlah batas demarkasi wilayah sementara yang disebut sebagai Garis Hijau ${ }^{78}$.

Rakyat Arab Palestina tadinya berharap persatuan negara-negara Arab merupakan penyelamat mereka, karena ketidakmampuan untuk berjuang sendiri akibat dampak dari kekalahan tahun 1936$1939^{79}$. Kenyataanya, mereka malah harus menyaksikan pasukan koalisi Arab saling bersaing satu sama lain, saling curigamencurigai, bahkan menyabotase divisi lainnya dengan sengaja ${ }^{80}$.

Hal ini ditekankan juga oleh Duta Besar Palestina untuk Republik Indonesia,

\footnotetext{
${ }^{76}$ Karsh, Efraim. The Arab-Israeli Conflict.The Palestine War 1948.(Oxford : Osprey Publishing,2002), h.51

${ }^{77}$ Surat Jamal al Hussayni untuk Delegasi PBB, Arab Higher Comitte Archive, 24 Mai 1948

${ }^{78}$ Nadim Rouhana, "The Intifada and the Palestinians of Israel: Resurrecting the Green Line", Journal of Palestine Studies, Vol. 19, No. 3 (Spring 1990), h. 58-75

${ }^{79}$ W.F. Abboushi. "The Road to Rebellion Arab Palestine in the 1930's". Journal of Palestine Studies. Vol.6 no.3 (Spring 1977),h.23-46

${ }^{80}$ Adeed Dawisha. Arab Nationalism in the Twentieth Century from Triumph to Despair. (New Jersey : Princeton University Press,2009), h. 130
} 
Fariz al Mehdawi : "Kekalahan pada Perang Tahun 1948 disebabkan karena kita kurang persiapan, terburu-buru dan bersikap emosional. Bangsa Indonesia saja Perlu 350 Tahun untuk merdeka dari Belanda, begitu halnya juga dengan India yang perlu waktu lama untuk bebas dari penjajahan Inggris, asal kita sabar dan tetap bertahan di tanah ini, pada akhirnya kita pasti bisa merdeka" ${ }^{\prime 1}$.

Dampak lain dari kekalahan pasukan koalisi Arab dalam perang tahun 1948 adalah eksodus rakyat Palestina dari tempat tinggalnya, baik karena mengungsi untuk menghindari pertempuran ataupun diusir dari rumahnya oleh pasukan IDF yang sedang melaksanakan 'Rencana Dalet'. Sebanyak 750.000 orang Arab Palestina menjadi pengungsi di Syria, Lebanon dan Jordania. Peristiwa terusirnya Bangsa Palestina pada hari itu disebut Nakba (Disaster Day) ${ }^{82}$.

\section{Pengambilalihan Hak Bangsa Palestina oleh Negara Arab Tetangga}

Akibat perang tahun 1948, Israel menguasai sebagian besar wilayah Palestina. Jordania kemudian menduduki wilayah yang dikenal sebagai Tepi Barat Sungai Jordan termasuk diantaranya Jerussalem Timur, dan beberapa kota seperti Jericho, Bethlehem, Hebron dan Nablus, sedangkan Jalur Gaza masih tetap berada dibawah kendali militer Mesir ${ }^{83}$.

Pemerintah Mesir mengusulkan agar dibentuk Pemerintahan untuk Palestina di

\footnotetext{
${ }^{81}$ Wawancara Pribadi dengan Duta Besar Palestina untuk Republik Indonesia, Fariz al Mehdawi, Jakarta 4 Juli 2014.

${ }^{82}$ Michael R Fischbach, The Impact of the 1948 Disaster: The Ways that the Nakba has Influenced Palestinian History, Paper for the International Symposium "The Transformation of Palestine: Palestine \& Palestinians 60 Years after the 'Nakba'", Berlin, March 8 and 9, 2010

${ }^{83}$ Christopher Catherwood. A Brief History of The Middle East : From Abraham to Arafat. (New York : Carrolf \& Graf Publishers,2006), h.194
}

wilayah-wilayah yang diduduki oleh pasukan Mesir dan pasukan Jordania, namun Jordania menolak usulan tersebut. Raja Abdullah dari Jordania lebih memilih untuk menggabungkan wilayah Tepi Barat Sungai Jordan ke dalam kekuasaannya, langkah ini mengundang protes dari seluruh anggota Liga Arab. Sementara pihak Jordania mengungkapkan bahwa rencana unifikasi tersebut bisa saja dibatalkan, dengan syarat, negara Arab lainnya tak boleh mendukung berdirinya sebuah pemerintahan yang dibuat oleh rakyat Palestina ${ }^{84}$.

Pada tanggal 23 September 1948, Pemerintah Mesir berinisiatif mendirikan "Pemerintah Seluruh Palestina" (alHukumat al-Filastini) di Jalur Gaza. Amin al-Hussayni didaulat untuk membacakan deklarasi kemerdekaan Palestina dan dilantik menjadi Presiden, Jerussalem dinyatakan sebagai ibukota negara Palestina yang baru. Walau demikian, bentuk negara ini terkesan ganjil karena mengklaim wewenang atas seluruh Palestina namun secara de-facto hanya berkuasa di Jalur Gaza. Pemerintahan ini juga tak memiliki kekuatan militer, tidak memiliki mata uang, tidak memiliki administrasi sipil, dan eksistensinya bergantung pada kebaikan hati Pemerintah Mesir $^{85}$.

Menanggapi tindakan Mesir itu, Raja Abdullah memilih melanjutkan rencana Unification of the Two Banks. Pada tanggal 1 Desember 1948, Konferesi Jericho menyatakan penggabungan Tepi Barat dengan Kerajaan Jordania atas dalih "Melindungi sisa wilayah Palestina dari ancaman Zionisme"; Raja Abdullah juga

\footnotetext{
84 Adeed Dawisha. Arab Nationalism in the Twentieth Century from Triumph to Despair. (New Jersey : Princeton University Press,2009), h.131

${ }^{85}$ Avi Shlaim. "Rise \& Fall of All Palestinian Government in Gaza".Journal of Palestine Studies. h.38-53
} 
diberikan gelar sebagai "Raja Seluruh Palestina"86.

Pada akhirnya, rakyat Palestina menemukan dirinya berada dalam situasi yang "complicated" akibat peristiwaperistiwa yang terjadi selama tahun 1948 . Mandat Inggris menyerah terhadap kasus Palestina, Negara Israel berdiri dan menduduki sebagian besar wilayah Palestina, sementara Mesir dan Jordania mengambil alih wilayah Palestina yang tersisa, adapun mayoritas rakyat Palestina terpaksa berdiaspora dan menjadi pengungsi di negara lain ${ }^{87}$.

Pengambilalihan hak-hak bangsa Palestina oleh negara-negara Arab tetangga merupakan sesuatu yang tak terhindarkan karena baik rakyat maupun elit Palestina membiarkan pihak lain yang berambisi untuk ikut campur dalam urusan internal bangsanya. Bagaimanapun dalam Politik tidak ada bantuan yang gratis. Apalagi beberapa negara anggota Liga Arab, baru berdiri sebagai sebuah negara merdeka, tentu mereka mengincar hegemoni untuk menjadi kekuatan politik terkuat di Timur Tengah. Kelemahan rakyat dan elit Palestina untuk memperjuangkan eksistensi negaranya dengan kekuatan sendiri serta sikap enggan mereka untuk menolak semua solusi yang ditawarkan Mandat Inggris dan PBB, dimanfaatkan oleh negara tetangga, seperti Mesir dan Jordania demi memenuhi hasrat akan supremasi.

Menurut Ibnu Burdah, Dosen Fakultas Adab UIN Sunan Kalijaga :

"Setiap jengkal diwilayah Timur Tengah adalah panggung terbuka bagi pertarungan antara para anggota Liga Arab yang ambisius. Setiap kekerasan yang

\footnotetext{
${ }^{86}$ Mahdi Abdul Hadi. Nakba : Procces of Palestinian Dispossession. (Jerussalem : Palestinian academic study of international affairs, 2008), h. 21

${ }^{87}$ Rashid Khalidi. Iron Cage : Palestinian Struggle for Statehood. (Oxford : One World Publication,2007), h.124
}

terjadi, bukan tak mungkin merupakan perbuatan salah satu anggota Liga Arab dari balik layar" ${ }^{\prime \prime 8}$.

Maka dapat kita simpulkan, bahwa apa yang terjadi di Palestina ketika itu sampai saat ini pun juga tak terlepas dari perbuatan negara Arab lainnya. Namun, sekali lagi, hal itu bisa terjadi karena kelengahan rakyat dan elit Palestina yang tak menjaga dirinya dengan baik dan membiarkan pihak lain yang berambisi untuk ikut bermain di halaman mereka.

\section{C.Penutup}

Lewat tulisan ini, penulis menyimpulkan penyebab kenapa Palestina gagal memerdekakan diri sedangkan Israel berhasil. Antara lain, bangsa Palestina tidak memanfaatkan kesempatan atau momentum dengan baik, karena selalu melakukan Pemberontakan,kerusuhan ataupun perlawanan melawan musuh yang masih kuat, dan usaha itu bukan hanya berbuah kegagalan, namun membuat musuh bangsa Palestina yaitu Zionis Yahudi memiliki alasan untuk mempersenjatai diri dan semakin memusuhi bangsa Palestina.

Akibat dari kegagalan tersebut, yang pertama, rakyat Arab Palestina kelelahan dan terlambat dalam memanfaatkan momentum hengkangnya Inggris pada tahun 1948, pihak Yahudi pun mengambil kesempatan itu dengan mendirikan negara Israel. Akibat kedua, rakyat Palestina terpaksa mengharapkan bantuan negaranegara Arab tetangga yang tergabung dalam Liga Arab, tidak banyak memberikan dukungan berarti bagi rakyat Palestina. Mereka juga tidak memiliki tentara yang terlatih dengan baik, sehingga dukungan yang mereka berikan kepada Palestina dalam peperangan berakhir dengan kegagalan.

\footnotetext{
${ }^{88}$ Ibnu Burdah. "KTT Liga Arab \& Masa Depan Arab”. Kompas. Rabu,2 April 2014. h.7
} 
Negara-negara anggota Liga Arab dan tentaranya ternyata lebih mementingkan hasrat politik dan keinginan menguasai daerah Palestina untuk kepentingan negaranya masing masing sehingga wilayah Palestina semakin berkurang, sisa wilayah Palestina yang tidak direbut oleh Israel, dicaplok oleh negara Arab yang membantunya, yaitu Mesir dan Yordania. 
